\title{
Electron transfer parameters for Methemoglobin formation in mutant Hemoglobin $\alpha$-chains.
} Vaibhav A. Dixit, ${ }^{*, a}$ Jochen Blumberger, ${ }^{b}$ and Shivam Kumar Vyas ${ }^{\mathrm{a}}$

${ }^{a}$ Department of Pharmacy, Birla Institute of Technology and Sciences Pilani (BITS-Pilani), Vidya Vihar Campus 41, Pilani, 333031, Rajasthan (India).E-mail: vaibhav.dixit@pilani.bits-pilani.ac.in, vaibhavadixit@gmail.com

${ }^{\mathrm{b}}$ Department of Physics and Astronomy, University College London, Gower Street, London WC1E 6BT, U.K. Email: j.blumberger@ucl.ac.uk

\section{Abstract}

Hemoglobin mediated transport of dioxygen $\left(\mathrm{O}_{2}\right)$ critically depends on the stability of the reduced $\left(\mathrm{Fe}^{2+}\right)$ form of the Heme cofactors. Some protein mutations stabilize oxidized $\left(\mathrm{Fe}^{3+}\right)$ state (Methemoglobin, $\mathrm{Hb} \mathrm{M}$ ) causing methemoglobinemia and can be lethal above $30 \%$. Majority of the analyses of factors influencing $\mathrm{Hb}$ oxidation are retrospective and give insights only for inner sphere mutations of Heme (His58, His87). Herein, we report the first all atom MD simulations on redox states and calculations of the Marcus ET parameters for the $\alpha$-chain $\mathrm{Hb}$ oxidation and reduction rates for $\mathrm{Hb} \mathrm{M}$. The $\mathrm{Hb}$ (wild type), and most of the studied $\alpha$-chain variants maintain globin structure except the $\mathrm{Hb} M$ Iwate $(\mathrm{H} 87 \mathrm{Y})$. Using linear response approximation we calculated average energy gaps $(\langle\Delta E\rangle)$, total $(\lambda)$, protein $\left(\lambda_{\text {prot }}\right)$, solvent $\left(\lambda_{\text {solv }}\right)$ reorganization energies, and redox potentials $\left(E^{\circ}\right)$, and oxidation free energies $\left(\Delta G^{\circ}\right)$. The total $\lambda$ ranges from $0.685-0.730 \mathrm{eV}$ in agreement with literature on $\mathrm{Hb}$ and similar Heme proteins. The mutants forming $\mathrm{Hb} \mathrm{M}$ tend to lower the $E^{\circ}$ and thus stabilize the oxidized $\left(\mathrm{Fe}^{3+}\right)$ state (e.g. the $\mathrm{Hb}$ Miyagi variant with K61E mutation). Solvent reorganization ( $\lambda_{\text {solv }} 73-96 \%$ ) makes major contributions to $\lambda$, while protein reorganization ( $\lambda_{\text {prot }}$ ) accounts for $27-30 \%$ except for the Miyagi and J-Buda variants $\left(\lambda_{\text {prot }} \sim 4 \%\right)$. Analysis of Heme-solvent $\mathrm{H}$-bonding interactions among variants provide insights into the role of Lys61 residue in stabilizing $\mathrm{Fe}^{2+}$ state and ET parameters. The ET parameters provide valuable insights into the $\mathrm{Hb}$ oxidation to $\mathrm{Hb} \mathrm{M}$ in agreement with the experimental data. Thus our methodology explains the effect of mutations on the structure, stability and $\mathrm{Hb}$ oxidation, and has potential for the prediction of methemoglobinemia. 


\section{Introduction}

Hemoglobin variants are wide spread in the Human population as seen in the HbVar database (http://globin.cse.psu.edu/hbvar/menu.html). These variants lead to two broad classes of disorders: 1) Globin synthesis and assembly disorders known as Thalassemias and 2) Globin structure disorders (Methemoglobinemia, Sickle cell anemia, and disorders caused by unstable, and altered dioxygen $\left(\mathrm{O}_{2}\right)$ affinity $\mathrm{Hb}$ variants). ${ }^{1} \mathrm{Hb}$ variant characterization, biochemical properties and associated clinical manifestations have been reviewed recently. ${ }^{2,3} \mathrm{Hb}$ is normally present in the reduced $\left(\mathrm{Fe}^{2+}, 99 \%\right)$ state and effectively transports $\mathrm{O}_{2}$ between lungs and tissues. In red blood cells (RBCs), the concentration of the oxidized $\mathrm{Hb}$, Methemoglobin (metHb, also known as $\mathrm{Hb} \mathrm{M}$ ), is kept below $1 \%$ by enzymatic (Cytochrome b5, and NADPH dependent Flavin reductase) and non-enzymatic (e.g. ascorbic acid) reductive pathways. ${ }^{4}$ Higher levels ( $\left.10 \%\right)$ can lead to cyanosis, reduced $\mathrm{O}_{2}$ delivery and level above $30 \%$ can be lethal. This condition, known as Methemoglobinemia, can be induced by drugs (chloroquine/hydroxychloroquine), inherited defects in Cytochrome b5 (or its reductase), or inheritance of an $\mathrm{Hb}$ variant characterized by an increase in the stability of oxidized (Ferric, $\mathrm{Fe}^{3+}$ ) or a decrease in the stability of the (ferrous, $\mathrm{Fe}^{2+}$ ) states. $^{5-10}$ Methemoglobinemia has been reported in many COVID-19 patients, ${ }^{11-13}$ thus potentially complicating the assessment of blood $\mathrm{O}_{2}$ saturation levels in respiratory distress. Incidence of COVID-19 in patients with sickle cell disease (characterized by $\mathrm{Hb} \mathrm{S}$ ) was found to be $85 \%$, but prevalence of other $\mathrm{Hb}$ variants in COVID-19 patients remains unexplored. ${ }^{14}$

A large body of information and knowledge is available in the form of more than 1820 known variants, > 600 human $\mathrm{Hb}$ structures in the PDB, a large number of biochemical, genetic, spectroelectrochemical, and modeling studies. The structure and function of $\mathrm{Hb}$ and impact of mutations on $\mathrm{O}_{2}$ affinity has been reviewed in the past. ${ }^{15-17}$ The $\mathrm{Hb}$ globin structure has eight helices that maintain a hydrophobic environment around the Heme and stabilize $\mathrm{Fe}^{2+}$ state to ensure reversible $\mathrm{O}_{2}$ binding. Structural changes that destabilize the goblin or expose Heme to solvent enhance oxidation rates and $\mathrm{Hb} \mathrm{M}$ formation. Robust clinical and biochemical tests (HPLC, Electrophoretic, MALDI-TOF and PCR), are available for the characterization of different variants, for example sickle cell $\mathrm{Hb}(\mathrm{Hb} \mathrm{S})$, and thalassemic forms ( $\mathrm{Hb} \mathrm{F}){ }^{3}$ but functional characterization of these variants in terms of $\mathrm{O}_{2}$ affinity or $\mathrm{Hb} \mathrm{M}$ content, oxidation, and reduction rates are extremely rare. ${ }^{18}$

Thus the in vivo rates for $\mathrm{Hb}$ oxidation to $\mathrm{Hb} \mathrm{M}$ and reduction of $\mathrm{Hb} \mathrm{M}$ back to $\mathrm{Fe}^{2+}$ state for many $\mathrm{Hb}$ variants remains unknown. These unknowns can potentially lead to failures in diagnosis, delays in the treatment, overtreatment and even cause treatment failures with standard therapy like methylene blue. ${ }^{9,19}$ Additionally, due to the lack of knowledge of factors like optimum reductant concentrations, and $\mathrm{O}_{2}$ pressures, $\mathrm{Hb} \mathrm{M}$ content can go unrecognized and reach toxic 
levels causing cyanosis and even fatality. Thus reliable estimation of the relative $\mathrm{Hb}$ oxidation and $\mathrm{Hb} \mathrm{M}$ reduction rates for different $\mathrm{Hb}$ variants is urgently required.

Marcus theory of electron transfer (ET) and its variants have been successfully applied in the areas of material science, small molecule charge-transfer complexes, redox heme and non-heme proteins involved in respiratory and mitochondrial ET chains. ${ }^{20}$ Since $\mathrm{Hb}$ is a tetramer with two identical $\alpha$ and $\beta$ chains which contain identical Iron-porphyrin (heme) co-factor, experimental measurements of enzymatic and non-enzymatic $\mathrm{Hb}$ reduction rates for individual subunits and applications of ET theories has proved challenging. McLendon et al., have used reconstituted [Zn, Fe] hybrid $\mathrm{Hb}$ dimers in which Heme-Fe in one of the chains has been replaced with znic. ${ }^{21}$ These hybrid $\mathrm{Hbs}$ show a larger free energy change $\left(\Delta \mathrm{G}^{\circ}\right)$ associated with the reduction (Equation 1) compared to the wild type $\mathrm{Hb}$. Using Marcus theory and assuming a constant reorganization energy of $(\lambda=0.9 \mathrm{~V})$ allowed the prediction of the ET rates $\left(k_{\mathrm{ET}}\right)$ for the wild and hybrid $\mathrm{Hb}$. The wild type $k_{\mathrm{ET}}=1.6 \mathrm{~s}^{-1}$ was predicted in close agreement with experimental value of 1 and $2 \mathrm{~s}^{-1}$ at $\mathrm{pH}=7$ and 6 respectively. ET rates from the photoinduced excited state of hybrid $\mathrm{Hb}$ were about 1500 fold faster due to a larger $\Delta \mathrm{G}^{\circ}$. Based on the binding constant $\left(\mathrm{k}_{\mathrm{b}}\right)$ and observed $k_{\mathrm{ET}}$, the authors concluded that formation of a specific biomolecular complex between Cyt b5 and $\mathrm{Hb}$ may not be necessary and ET takes places via a simple biomolecular collision mechanism.

$$
\text { Cyt } b 5\left(F e^{2+}\right)+H b M\left(F e^{3+}\right) \rightarrow C y t b 5\left(F e^{3+}\right)+H b\left(F e^{2+}\right)
$$

Equation 1

Earlier studies by Mauk et al., had found contrasting spectroscopic evidence with quantitative formation of 1:1 Cyt b5:Hb complexes. ${ }^{22}$ Extending this work they proposed a model for the Cyt b5:Hb complex in which the Heme edges are $8 \AA$ apart while the Fe-Fe distance in the complex was $16 \AA^{23} \mathrm{Hb}$ residues (Lys 54, 56, 60, 61, 90, heme propionates) and Cyt b5 residues (Glu 43, 44,48, ASP 60 , and heme propionates) were postulated to be involved in complex formation. Later Hoffman et al., used similar $\mathrm{Hb}$ hybrids and determined the ET rates for individual $\mathrm{Hb}$ subunits. ${ }^{24}$ The $\alpha$ subunit showed 4 fold higher binding affinity and 2 fold faster ET rates compared to the $\beta$ subunits. These findings were similar to earlier reports of the ET between $\mathrm{Hb}$ and inorganic complexes. ${ }^{25}$ Brittan et al., performed Brownian dynamics and electrostatics calculations to reassess the structural requirements for efficient electron transfer between Cyt b5 and embryonic $\mathrm{Hb}^{26}$ Although there was a descent agreement with Mauk et al, ${ }^{22}$ regarding the identity of residues involved in the complex formation, the ET rates were overestimated for the native $\mathrm{Hb}$ and were similar to the hybrid $\mathrm{Hb}$. None of these studies have performed all atom MD simulations of the redox states to estimate Marcus parameters and ET rates.

The experimental redox potentials $\left(E^{\circ}\right)$ for $\mathrm{Hb}$ and $\mathrm{Hb}$ subunits depend on the details of the experimental method (direct electrochemistry, or spectroelectrochemistry), nature of the electrodes and its interactions with $\mathrm{Hb}$, and conditions e.g. presence of $\mathrm{O}_{2}, \mathrm{pH}$ (Bohr effect), ionic 
strength, redox mediator, and temperature. Literature values range from -0.172 to $+0.050 \mathrm{~V}$. In studies with the $\mathrm{Hb}$ tetramer, the identity of the subunits undergoing the redox changes are uncertain. Earlier Mateescu et al., have performed cyclic voltammetry experiments to determine the $\mathrm{Hb} E^{\circ} \mathrm{s}$ under acidic/aerobic and neutral/anaerobic conditions which are known to stabilize the $\mathrm{T}$ (tense) and $\mathrm{R}$ (relaxed) states respectively. ${ }^{27}$ The authors assigned $E^{\circ}$ values of -0.040 and $-0.165 \mathrm{~V}$ respectively to the $\mathrm{R}$ and $\mathrm{T}$ states of $\mathrm{Hb}$. Guiles et al, have measured the $E^{\circ}$ of $\mathrm{Hb}, \mathrm{Cyt}$ b5 and used Marcus theory to predict reorganization energies $(\lambda)$ and homogenous and heterogenous ET rates. ${ }^{28}$ Similar variations in the $E^{\circ}$ s were observed in the presence and absence of $\mathrm{O}_{2}$ which are characteristic of $\mathrm{R}$ and $\mathrm{T}$ states.

A combination of quantum chemical calculations and MD simulations have been used to estimate Marcus ET parameters $\left(\lambda, \Delta G^{\circ}\right)$ and ET rates for many redox proteins. ${ }^{29-34}$ These methods make use of the linear response approximation to estimate the free energy parabolas which allows the estimation of $\lambda$, and $\Delta G^{\circ}$ from the thermal averages of the energy gaps $(\langle\Delta E\rangle)$ for the oxidized $(O)$ and reduced $(R)$ states. ${ }^{31}$ ET rates can then be predicted using either the full estimation of electronic coupling matrix and Frank-Condon factors or using empirical parameters for protein packing density along with the Marcus parameters. ${ }^{35,36}$ Studies with other redox proteins have shown that mutations both within and outside the active sites lead to significant changes in the Marcus parameters which ultimately modulate the ET rates and protein functions. ${ }^{35,36,37,38} \mathrm{MD}$ simulations for the native $\mathrm{Hb}$ have been reported earlier. ${ }^{39-45}$ These, mostly focused on the allosteric mechanisms of ligand binding and $T \rightarrow R$ transitions. More recently Case and Samuel have studied the dynamics of $\mathrm{Hb} \mathrm{M}$ and associated Heme loss. ${ }^{46}$ But the measurement or estimations of the Marcus parameters and ET rates for $\mathrm{Hb}$ and its variants using all atom MD simulations have not been reported till date and represent gaps in our understanding of how globin mutations influence $\mathrm{Hb}$ oxidation, reduction and $\mathrm{Hb} \mathrm{M}$ content via modulation of $\mathrm{ET}$ parameters. Reliable predictions of ET parameters for $\mathrm{Hb}$ and its variants can provide atomic level and functional insights into factors influencing $\mathrm{Hb}$ oxidation. This information can prove valuable in identifying potential $\mathrm{Hb}$ variants with increased propensity for oxidation and $\mathrm{Hb} \mathrm{M}$ formation. It may also prove useful in the design of novel alternative therapeutic interventions in populations where classical therapy (e.g. methylene blue) is contraindicated. Indeed the design of safer blood substitutes has been attempted, but clinical development has often been hampered by Heme-oxidation induced toxicity. ${ }^{47,48}$

In this work, we performed all atom MD simulations on the wild type and variant $\alpha \mathrm{Hb}$ chains for the estimation of Marcus ET parameters $\left(\lambda, \Delta G^{\circ}\right)$, and redox potential $\left(E^{\circ}\right)$. We address the following key questions with respect to estimation of $\mathrm{Hb}$ oxidation among selected $\mathrm{Hb}$ variants. 1) What is the influence of $\mathrm{Hb} M$ stabilizing $\alpha$ chain mutations on the globin structure and stability? 2) Can a protocol utilizing quantum chemically derived parameters and all atom MD simulations provide insights into the experimentally observed Marcus parameters $\left(\lambda, \Delta G^{\circ}\right)$ for 
wild type $\alpha \mathrm{Hb}$ chain and its redox partner Cyt b5? 3) What is the influence of $\mathrm{Hb} \mathrm{M}$ stabilizing mutations on the ET parameters? 4) How do these mutations affect outer-sphere (including protein and solvent) reorganization energies (namely, and $\lambda_{\mathrm{os}}=\lambda_{\text {prot }}+\lambda_{\text {solv }}$ ) and the driving force $\left(\Delta G^{\circ}\right)$ ?

\section{Methodology}

\subsection{Protein preparation}

Hemoglobin $(\mathrm{Hb}) \alpha$ chain coordinates were extracted from T state structure $1 \mathrm{HGA}$ (A chain). ${ }^{49,50}$ This structure represents the deoxy- $\mathrm{Hb}$ in the T state. As seen in Figure 1 alignment of the protein backbone of this structure with the oxidized methemoglobin ( $\mathrm{Hb} M, 1 \mathrm{HGB}$ shows very similar structure (backbone and all atom RMSD $=0.186,0.233 \AA$ ). Thus 1 HGA structure was chosen for further analysis. The protonation states for the protein chain were estimated at $\mathrm{pH}=7.4$ with $\mathrm{H}++3.0^{51}$ via its webserver. ${ }^{52}$ Total charge on the globin chain was +1 at this $\mathrm{pH}$. For Cyt b5 modeling, the $3 \mathrm{NER}^{53}$ structure was selected and protein was prepared for MD simulations using a procedure similar. Total charge on the Cyt b5 structure was -10 at $\mathrm{pH}=7.4$.

\subsection{Heme parameterization with MCBP.py and quantum chemical calculations}

Metal Center Bond Parameter python tool (MCBP.py) ${ }^{54}$ available in AmberTools $18^{55}$ was used for Heme and axial ligand parameterization in both the redox states of $\mathrm{Cyt} \mathrm{b} 5, \mathrm{Hb}$ and $\mathrm{Hb}$ variants. A procedure similar to that described for the CYP450 BM3 (Amber advanced tutorial http://ambermd.org/tutorials/advanced/tutorial20/mcpbpy heme.htm) was used (see Supporting information for details).

\subsection{Equilibration and production simulations}

A robust ten-step protocol recently reported by Roe and Brooks was used to equilibrate the structures of $\mathrm{Hb} \alpha$ chains, its variants, Cyt b5 and Cyt b5:Hb complex studied in the present work. ${ }^{56}$ Briefly, step 1 involved minimization of solvent while keeping strong $(5.0 \mathrm{kcal} / \mathrm{mol} \AA)$ restraints on the protein, porphyrin ring, Iron and the axial ligand. In Step 2, a short 15 ps MD with NVT, weak-coupling thermostat was performed while retaining the restraints. Step 3, was 1000 steps of minimization with weaker $(2.0 \mathrm{kcal} / \mathrm{mol} \AA)$ restraints on the same atom selection. Step 4, continued minimization for 1000 steps with even weaker $(0.1 \mathrm{kcal} / \mathrm{mol} \AA)$ restraints on the same atom selection. Step 5, final minimization for 1000 steps without any restraints. Step 6 was MD for $5 \mathrm{ps}$, with moderate $(1.0 \mathrm{kcal} / \mathrm{mol} \AA)$ restraints on the same atom selection using NPT ensemble. Step 7 and 8 were additional relaxation for 5 and 10 ps respectively with NPT and smaller $(0.5 \mathrm{kcal} / \mathrm{mol} \AA)$ restraints. Step 9, involved unrestrained relaxation for $10 \mathrm{ps}$. The final density equilibration was performed in $1 \mathrm{~ns}$ increments without any restraints under periodic boundary conditions, hydrogens were restrained with SHAKE on, a collision frequency was set to $5 \mathrm{ps}^{-1}$ as recommended for Langevin thermostat and temperature was set to $300 \mathrm{~K}$. This protocol defines three parameter values as a robust criteria for declaring the equilibration success. The 
criteria are 1) the value for the slope of the density vs. time plot should be less than $10^{-6} .2$ ) The final density of the system should not differ from the average of the second half of the density data by more than $0.02 \mathrm{~g} \mathrm{~cm}^{-3}$. 3) The fitted exponential chi square value should be less than 0.5 . All the structure simulated in the present work passed these criteria and thus were used for production runs and further analysis. This protocol available via AmberMDPrep shell script requires the latest version of cpptraj (V4.30.2) which was installed from GitHub and sourced before running the protocol. ${ }^{57}$

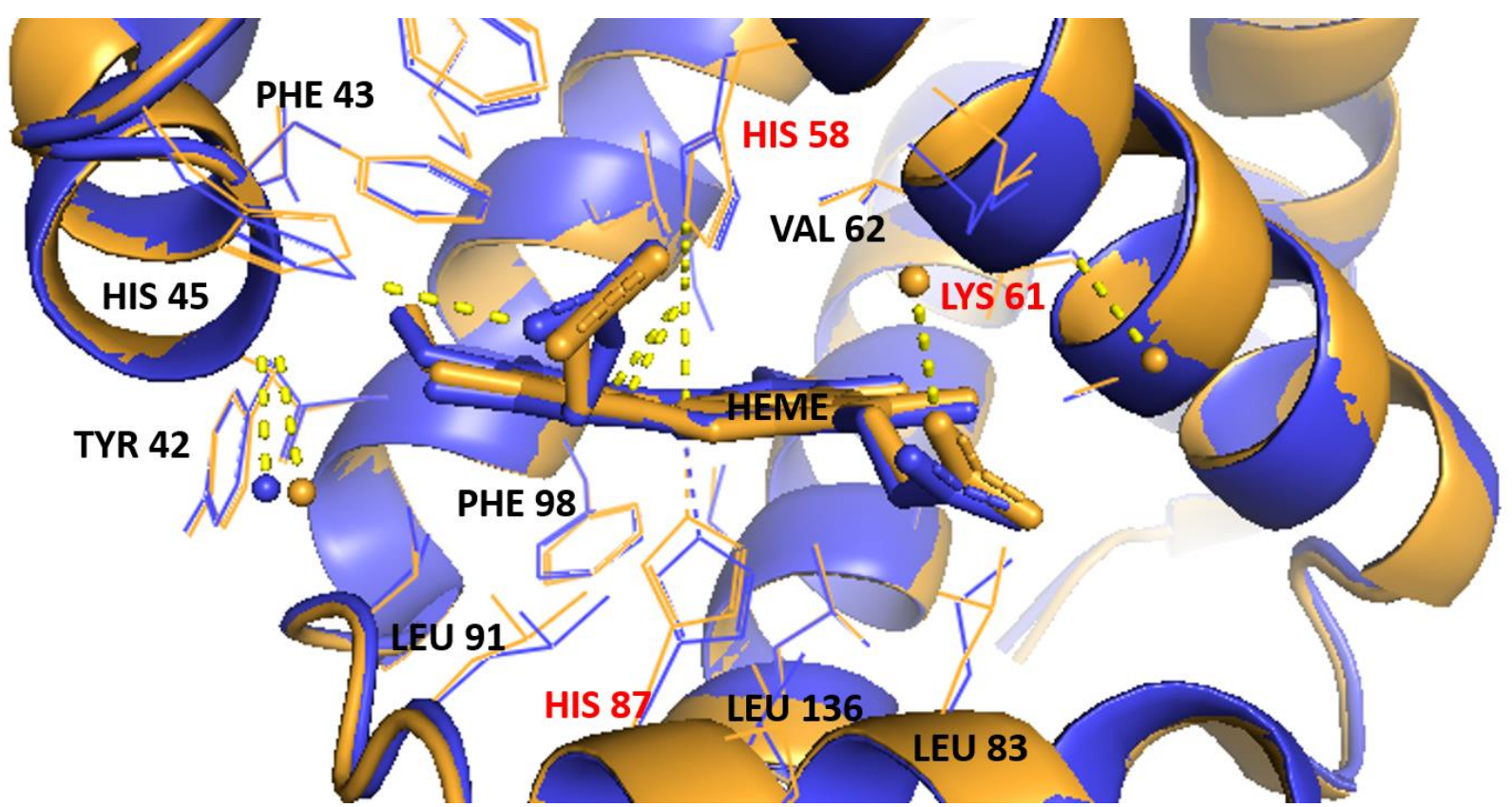

Figure 1. Alignment of $\alpha$ chains of hemoglobin structures in the reduced (1HGA, blue) and oxidized (1HGB, light orange) states. The Fe-N(HIS 87) distances in 1 HGA and 1 HGB are 2.214 and 2.153 A respectively. The corresponding Fe-N(HIS 58) distances are 4.444 and $4.303 \AA$. These parameters are in agreement with the geometry of Heme complexes where the Fe is displaced out of the plane of the porphyrin ring unless coordinated with additional axial ligands like $\mathrm{O}_{2}$ and the oxidized state is low spin hexa coordinate usually interacts with water or with HIS 58. Dashed light yellow lines indicate that residues interact with each other. Amino acids in red-color indicate mutation sites studied in this work.

The structures for the $\mathrm{Hb}$ variants were prepared by renaming the chosen backbone residue names and deleting the sidechain atoms from the PDB file. The mutant side-chain rotamers without clashes and highest probability were selected from the Dunbrack's rotamer library available in Chimera. ${ }^{58,59}$ Identical protocols were used for equilibrating the $\mathrm{Hb}$ variant $\alpha$ chains in both redox $\left(\mathrm{Fe}^{2+}\right.$ and $\left.\mathrm{Fe}^{3+}\right)$ states. The summary of mutation categories in the Hbvar database contains information on $363 \alpha$ chain variants. The summary table also gives 13 variants classified as Methemoglobins, 4 of which are $\alpha$ chain variants. Nonetheless, many of the $363 \alpha$ chain variants (not classified in the database as Methemoglobins), do form $\mathrm{Hb} \mathrm{M}$. Thus we additionally selected variants which have been characterized in the literature ${ }^{60}$ and are known to form methemoglobin ( $\mathrm{Hb} \mathrm{M}$ ) and/or lower the concentration of reduced $\mathrm{Hb}$ namely, $\mathrm{Hb} \mathrm{M}$ Boston 
(H58Y), Hb M Iwate (H87Y), Hb Miyagi (K61E) and Hb Kirklareli (H58L). Additionally, a single point mutant which does not lead to $\mathrm{Hb}$ M formation, $\mathrm{Hb}$ J-Buda (K61N), was studied.

\section{Results and Discussion}

Reduction of the monomeric native $\alpha \mathrm{Hb}$ chain has been studied earlier. ${ }^{62,63}$ These studies found that the redox behavior of the $\alpha \mathrm{Hb}$ chain in monomeric state is almost identical to the $\mathrm{Hb}$ tetramer. Thus studying the effect of $\alpha \mathrm{Hb}$ monomer on the Marcus parameters is justified and can be expected to meaningfully represent the ET and redox processes in the tetramer. As noted by Hub et al., most of the experimental studies monitor the hydrogen bond dynamics between a small set of selected inter-chain residues e.g. $\alpha$ Asp94- $\beta$ Trp37 and $\alpha$ Tyr42- $\beta$ Asp99. ${ }^{41}$ These interactions are interpreted in terms of conformal $(T \leftrightarrow R)$ transitions without further investigations. NMR studies in solution have identified $\alpha$ chain His45, Tyr42, Thr41, His89, His50, His72 residues play an important role in Bohr effect while residues around Asp94 and His122 participate in $\alpha 1 \beta 2$ subunit interactions. ${ }^{17}$

With this background the results and discussion is divided into four main subsections; 3.1. Influence of $\mathrm{Hb} \alpha$-chain mutations on the structure and stability, 3.2. Marcus ET parameters and redox potential $\left(E^{\circ}\right)$ for the wild type $H b, 3.3$. Marcus $E T$ parameters $\left(\lambda, \Delta G^{\circ}\right)$ and redox potential $\left(E^{\circ}\right)$ for selected $\mathrm{Hb}$ variants, 3.4. Contributions of protein and solvent to the reorganization energies, 3.5. Marcus ET parameters for the Cyt b5 (the redox partner of $\mathrm{Hb}$ ).

\subsection{Influence of $\mathrm{Hb} \alpha$-chain mutations on the structure and stability}

Realizing the dynamical nature of $\mathrm{Hb} \alpha$ chain interactions the effect of $\mathrm{Hb} \mathrm{M}$ stabilizing mutations on the dynamics and flexibility of various globin regions was investigated. Residue wise backbone root mean square fluctuations (RMSF) on the equilibrated trajectories (40 ns) were calculated with cpptraj (as seen in Figure 2). As expected the $\mathrm{N}$ and $\mathrm{C}$-terminals show higher fluctuations. $\mathrm{A}$ comparison of the RMSF for residues $\sim 10-130$ shows that the overall globin structure is similar among variants except the $\mathrm{Hb} \mathrm{M}$ Iwate which involves mutation of the axial Histidine ligand with Tyrosine (H87Y). This mutation is known to destabilize the Heme globin structure and function. ${ }^{64}$

To assess the influence of other mutations which show a stable globin structure but nonetheless oxidize to $\mathrm{Hb} \mathrm{M}$, the RMSF values among their redox states were compared. For this a student T-test matrix among all the variants was calculated (See Table S1, Supporting Information). Residue-wise RMS fluctuations (RMSF) are considered similar for pairs that show a $\mathrm{P}$ value more than 0.05 . Mutation of the distal Histidine with Tyrosine (H58Y) seen with the Boston $\mathrm{Hb}$ variant maintains the overall globin structure. The largest backbone fluctuations are in the residues 44$54,89,90$, and $114-119$ (see Figure 2). The region 44-54 is a loop that has important hydrophobic (Phe43, 46-Heme) and electrostatic (His45-Heme carboxylate) interactions that stabilize the Heme in the wild type. Whereas the region 114-119 has key interactions with the $\beta$ chain residues (Arg30, and His116). The RMSF (excluding four terminal residues) for the redox state 
between native and $\mathrm{H} 58 \mathrm{Y}$ variant shows that fluctuations are significantly different and the average, min, max and stdev are larger for the H58Y variant (Table S1 and S2, see supporting information). This indicates that this mutation destabilizes both the redox states.

Mutation of the His58 to Arg, analogous to the H58R Zurich variant of the $\beta$ chain, shows similarly large variations in these regions in addition to a larger fluctuation in the loop 117-120. These findings are consistent with the large size of the Arg side chain (similar to Tyr) which leads to similar motions of these regions as manifested by higher RMSF value (see Figure 2). The fluctuations induced by H58R mutation are significantly different and average values are about twice from the wild type $\mathrm{Hb}$ (Table S1 and S2).

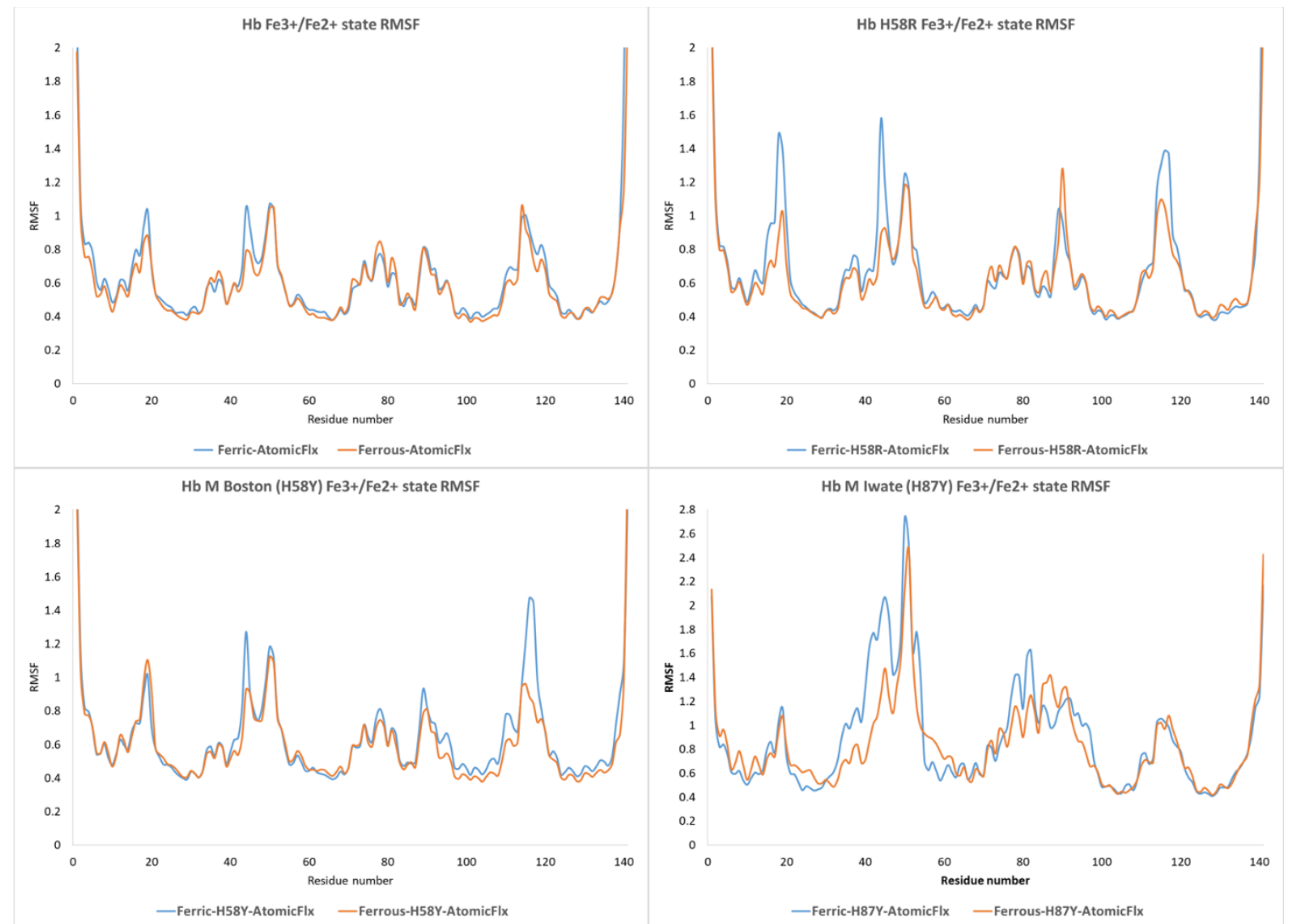

Figure 2. RMSF for the protein backbone for the wild type $\mathrm{Hb}$, mutants leading to the formation of Hb M (Iwate and Boston variants) and H58R mutant which is analogous to the 6 chain Hb Zurich variant. The RMSF was calculated for 2000 snapshots extracted from a 40 ns MD trajectory.

A close inspection of the globin and Heme structure in $\mathrm{Hb} \mathrm{M}$ Iwate during the MD simulation, shows that the Heme group significantly moves out of the protein pocked and gets exposed to the solvent medium (see Figure $\mathrm{S} 1$ ). It is known in the literature that the $\mathrm{Hb} \mathrm{M}$ Iwate structure is not stable and there is experimental evidence that the Heme group gets transferred to the distal histidine in the reduced state. ${ }^{64}$ Considering the large structural changes that H87Y mutation induces in the $\mathrm{Hb}$ structure and the lack of crystal structure we choose not to use these MD 
trajectories to investigate the effect on Marcus parameters, oxidation activation energies and ET rates for this variant.

The RMSF analysis for the $\mathrm{Hb}$ Miyagi and Kirklareli variants (K61E and $\mathrm{H} 58 \mathrm{~L}$ ) which are known to form $\mathrm{Hb}$ M showed similar RMSF (pairwise) compared to the reduced $\left(\mathrm{Fe}^{2+}\right)$ and oxidized $\left(\mathrm{Fe}^{3+}\right)$ native $\mathrm{Hb}$. The average reduced $\left(\mathrm{Fe}^{2+}\right) \mathrm{RMSF}$ is larger than the oxidized $\left(\mathrm{Fe}^{3+}\right)$ state for both the variants (Table S1 and S2). This is in contrast to the native and other $\mathrm{Hb}$ variants suggesting that the reduced state fluctuations are higher in these variants. Recently a crystal structure (3QJD) for the Kirklareli variant has been reported. ${ }^{65}$ Pairwise CA atom RMSD between the 1 HGA and 3QJD is $1.00 \AA$, suggesting that the mutant adopts a similar globin structure (see Figure S3). MD simulations starting from this structure showed similar trends in RMSF. Nonetheless, the $\mathrm{Fe}^{2+}$ state showed larger fluctuations for polar residues Asn78, His89 and Lys90. This suggests that the His58 interactions with Heme stabilize the movement of proximal residues and mutation to a non-polar Leucine thus increases the dynamics of these residues. The $\mathrm{Fe}^{3+}$ state, on the other hand, had higher RMSF in the loop region (residues 114-117). In contrast the Hb J-Buda variant with a semi-conservative mutation (K61N) which showed minor fluctuations in the Heme interacting loop (residues 44-54). Whereas relatively larger differences in fluctuations are observed in the region 115-120 which indicates weaker interactions with the $\beta$ chain (especially in the oxidized state, see Figure 3). Except for the K61E, H58L variants, the RMSF values are consistently higher for the oxidized $\left(\mathrm{Fe}^{3+}\right)$ state. This can be understood by considering the reduction in the electrostatic repulsion between the Glu side-chain and the Heme group in the oxidized state. These findings suggest that mutation in one region of the $\mathrm{Hb}$ can have significant influence on the dynamics in distant regions. ${ }^{66,67}$ 


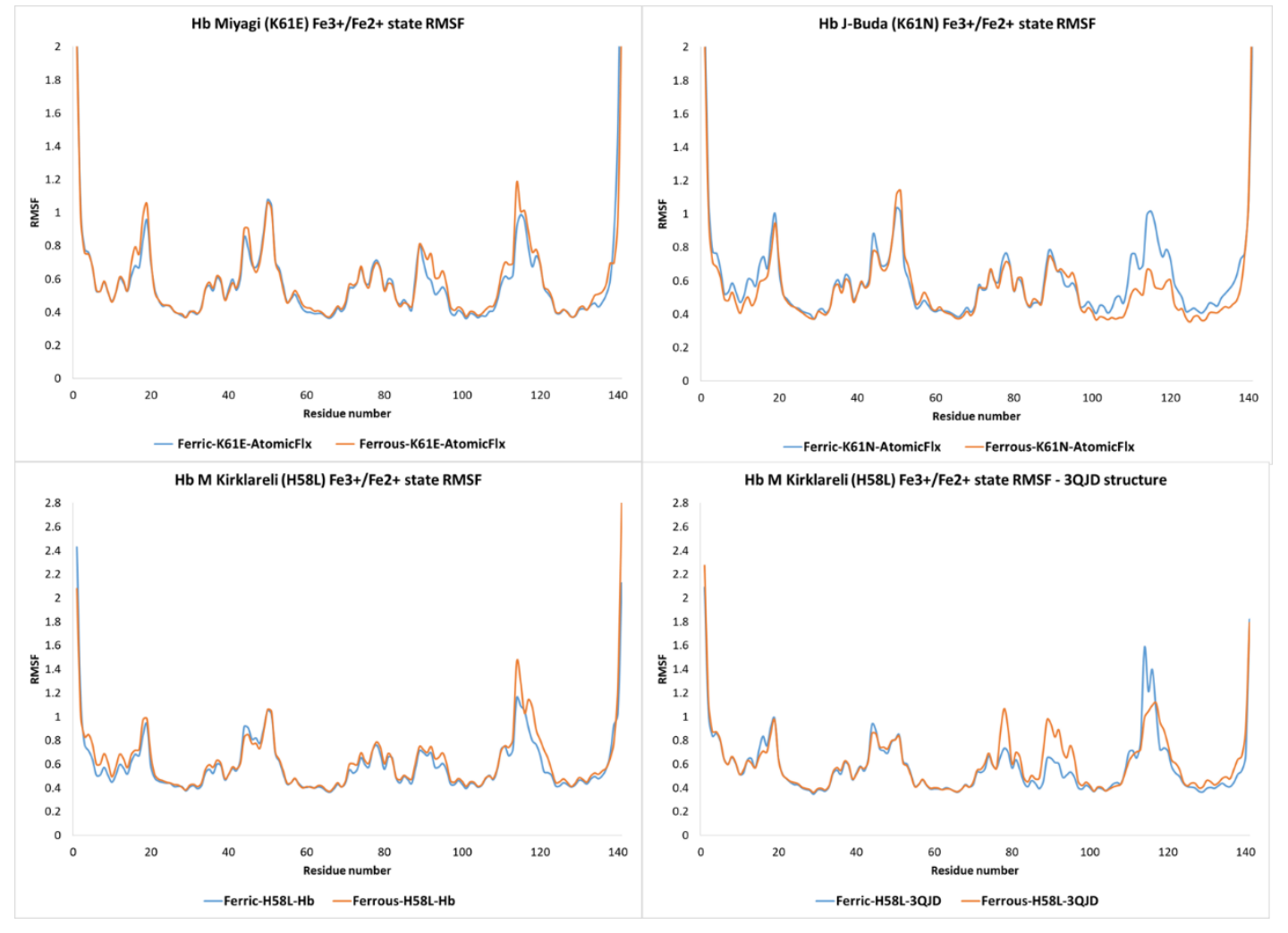

Figure 3. Residue wise RMSF for the protein backbone for the Hb variants in the oxidized (Ferric) and reduced (Ferrous) states during the $40 \mathrm{~ns} \mathrm{MD}$ simulations. The Hb Miyagi (K61E) and Hb Kirklareli variants forms $\mathrm{Hb} \mathrm{M}$, while the Hb J-Buda (K61N) variant functions normally.

A comparison of the RMSD for the $\mathrm{Hb}$ redox states similarly shows that the variant leading to $\mathrm{Hb}$ $M$ formation results in the largest movement in the protein backbone (see supporting information Figures S1-S9).

\subsection{Marcus ET parameters and redox potential $\left(E^{\circ}\right)$ for the wild type $\mathrm{Hb}$}

Since different mutations lead to different $\mathrm{Hb}$ reduction rates and different equilibrium $\mathrm{Hb} \mathrm{M}$ content, we tested if there is a correspondence between these and the Marcus ET parameters. As mentioned in the introduction MD trajectories have been used earlier along with the linear response approximation to determine Marcus ET parameters $\left(\lambda, \Delta \mathrm{G}^{\circ}\right)$ and ET barriers for redox proteins. Similar to such proteins, in the Heme proteins small changes in system charges are distributed over large number of atoms (porphyrin ring, axial His, and residues within nonbonded interaction distances). For example the inner sphere contribution to reorganization energy was estimated to be only $50 \mathrm{meV}$ in cytochrome MtrF (a decaheme bacterial redox protein complex). ${ }^{68}$ Similar to $\mathrm{Hb}$, the Cyt MtrF Hemes are partially solvent exposed and are known to exhibit $\lambda$ in the range $0.75-1.1 \mathrm{eV}$. Thus it is reasonable to expect that the variations in the structure and dynamics of the $\mathrm{Hb}$ Hemes will contribute only a small fraction $(<5 \%)$ to the total reorganization energy (i.e. $\lambda>>\lambda_{\text {is, }}$ where subscript "is" represents inner coordination sphere of the metal center). The most important contributions come from the protein $\left(\lambda_{\text {prot }}\right)$ and the solvent $\left(\lambda_{\text {solv }}\right)$ environments which together constitute the outer sphere reorganization 
energies $\left(\lambda \sim \lambda_{\text {os }}=\lambda_{\text {prot }}+\lambda_{\text {solv }}\right)$. Thus these $\lambda$ values were estimated by taking the thermal averages of the AMBER force field energies calculated by the post-processing of MD trajectories with cpptraj. The sander program (parallel version) was used to calculate the energy gaps in periodic conditions similar to those used for MD simulation. The $\lambda_{\text {prot }}$ was obtained by stripping water molecules and counter ions from the trajectory and recalculating the AMBER force field energies.

The mutations studied in this work are within the $\mathrm{Hb}$ active site and previous docking models of the Hb-Cyt b5 complexes have estimated a Heme edge to edge distance of $\sim 8 \AA .69$ Thus it is reasonable to expect that the relative $\mathrm{Hb} \mathrm{M}$ reduction rates and content would correspond to relative changes in $\mathrm{Hb}$ redox properties. Since $\mathrm{Hb}$ oxidation to $\mathrm{Hb} \mathrm{M}$ is known to occur via multiple enzymatic or non-enzymatic steps, the redox process can be simulated as a one-step oxidation process for a single ionizable group shown in Equation 2. ${ }^{32}$ Using this formalism and the linear response approximation the $\lambda$ s are equated to the half of the differences in the average vertical ionization energies ( $\left\langle\Delta E_{M}\right\rangle$, called the average energy gaps) for the redox states $(M=R$, $0)$. These average energy gaps are calculated using $\left\langle\Delta E_{M}\right\rangle=\left\langle E_{O}\right\rangle-\left\langle E_{R}\right\rangle$, where $\left\langle E_{M}\right\rangle$ are the Boltzmann average potential energies of the $M$ state calculated using AMBER force field parameters for the $O$ and $R$ redox states respectively. ${ }^{32}$ The free energy changes $\left(\Delta A^{\circ} \sim \Delta G^{\circ}\right)$ are equated to the mean of these energies gaps (see equations 2-19 in reference ${ }^{32}$ and equations 13-15 in reference ${ }^{31}$ ).

$$
\text { Redued } H b(R) \rightarrow \text { Oxdized } H b(O)+e^{-}
$$

Equation 2.

Table 1 below shows the average vertical ionization energies $(<\Delta E\rangle)$ for the redox states, Marcus parameters $\left(\lambda, \Delta G^{\circ}\right)$, and the redox potential $\left(E^{\circ}\right)$. Since the non-polarizable force fields are known to systematically overestimate reorganization energies, a factor of 1.6 , recommended by Blumberger was used to scale $\lambda$ values. ${ }^{31}$ The scaled $\lambda$ are discussed here onwards (except in section 3.4, where relative changes in protein and solvent contribution are discussed).

The wild type $\mathrm{Hb}$ showed vertical ionization energies $(\Delta \mathrm{E})$ of 0.91 and $3.10 \mathrm{eV}$ in the oxidized and reduced states respectively (see Table S3). This gives a reorganization energy $(\lambda)$ for the wild type $\mathrm{Hb} 0.6853 \mathrm{eV}$, which is lower than the value reported by Blankman et al., for the $\mathrm{Hb}$ tetramer. ${ }^{28}$ It should be noted that the values for the $\mathrm{Hb}$ tetramer include $\lambda$ contributions from the $\beta$ subunit and is known to undergo larger structural changes upon ligand binding and hence increase the $\lambda$ in the tetrameric complex (Figure $8 a, 10$ of reference ${ }^{40}$ ). 
Table 1. The total reorganization free energies ( $\lambda$ in eV, scaling factor 1.6$){ }^{31}$ redox potential $\left(E^{\circ}\right.$, $V)$, for $\mathrm{Hb}$, Cyt b5, and selected $\alpha$ chain Hb mutants.

\begin{tabular}{|c|c|c|c|c|}
\hline Protein & Mutation & $\lambda$ & $E^{\circ}$ & Hb M formation \\
\hline $\mathrm{Hb}$ & Wild & 0.6853 & $-0.165^{a}$ & $<1 \%$ \\
\hline $\begin{array}{l}\alpha \text { analogue of the } \\
\mathrm{Hb} \text { Zurich } \beta \text { variant }\end{array}$ & H58R & 0.7216 & -0.064 & NA \\
\hline Hb Miyagi & K61E & 0.7297 & -0.296 & $\begin{array}{l}\text { Increased } \mathrm{Hb} \mathrm{M} \\
\text { formation }\end{array}$ \\
\hline Hb J-Buda & K61N & 0.6692 & -0.204 & NA \\
\hline Hb Kirklareli & H58L & 0.7001 & -0.176 & \\
\hline Hb Kirklareli (3QJD) & H58L & 0.6867 & -0.150 & \\
\hline Cyt b5 (3NER) & Wild & 0.9299 & -0.212 & Not applicable \\
\hline
\end{tabular}

Moreover our estimates for $\alpha \mathrm{Hb}, \lambda$ are slightly lower than Heme complexes with relatively higher solvent exposure. ${ }^{68}$ These agreements in the calculated ET parameters with the experimental data lend support to our modeling approach.

As mentioned above a redox potential ( $E^{\circ}$ vs NHE) of $-0.165 \mathrm{~V}$ has been reported in the literature for the T-state $\mathrm{Hb}^{27}$ Thus $\Delta \mathrm{G}^{\circ}$ predictions for $\mathrm{Hb}$ were scaled to match the experimental data. Further using these values a good estimate for the biologically relevant ET from Cyt b5 to Hb can be modelled using the computed Cyt b5 $\lambda=0.9299 \mathrm{eV}$ (see section 3.5). The experimental electrochemical $\lambda=0.44 \mathrm{eV}^{28}$ is smaller than reported for similar proteins earlier ${ }^{32}$ most probably due to adsorption of the Cyt b5 on the electrode surface which reduces the protein motion significantly. Thus the relative changes in the Marcus ET parameters and redox potential in different $\mathrm{Hb}$ variants with and without an increased tendency to form methemoglobin ( $\mathrm{Hb} \mathrm{M}$ ) are discussed in the next section.

\subsection{Marcus ET parameters $\left(\lambda, \Delta \mathrm{G}^{\circ}\right)$ and redox potential $\left(E^{\circ}\right)$ for selected $\mathrm{Hb}$ variants}

The variants resulting from the mutation of residues in the ligand binding sites are known to affect $\mathrm{O}_{2}$ affinity, $\mathrm{Hb}$ function and often increase the $\mathrm{Hb} \mathrm{M}$ content. ${ }^{2}$ Thus we investigated the 
influence of selected mutations on ET parameters, oxidation free energies and redox potential $\left(E^{\circ}\right)$. The mutation of the distal Histidine with Tyrosine ( $\left.\mathrm{H} 58 \mathrm{Y}\right)$ leads to the $\mathrm{Hb} \mathrm{M}$ Boston variant. It shows larger $\lambda(\sim 0.792 \mathrm{eV})$ but a similar free energy change $\left(\Delta \mathrm{G}^{\circ}\right)$ and $E^{\circ}$ compared to the wild type which might make its experimental assignment difficult. Raman spectroscopic studies on the $\mathrm{Hb}$ Boston and Iwate variants have shown that these variants involve the coordination of the Heme with distal ligands which was not modelled explicitly here.

Nonetheless, modern force field based MD simulations are expected to capture the out sphere effects on ET parameters. The influence of the mutation of distal Histidine to a non-coordinating Arginine residue (H58R) on ET parameters and redox potential was studied. As seen in Table 1, this variant shows larger $\lambda(0.7216 \mathrm{eV})$, and $\Delta \mathrm{G}^{\circ}(2.105 \mathrm{eV})$ values giving higher redox potential $\left(E^{\circ}=0.064 \mathrm{~V}\right)$ than the wild type $\mathrm{Hb}$. These parameter values indicates a lower equilibrium concentration of $\mathrm{Hb} \mathrm{M}$ for this variant. Although, this variant has not been reported in the literature yet, its $\beta$ analogue, the $\mathrm{Hb}$ Zurich variant, has been found to be susceptible to oxidation ( $\mathrm{HbVar}$ database). Our results suggest that this $\mathrm{Hb}$ (H58R) variant may not lead to a noticeable change in the background $\mathrm{Hb} \mathrm{M}$ content. In contrast the $\mathrm{Hb}$ Kirklareli variant has been reported to undergo oxidation to $\mathrm{Hb} \mathrm{M} \mathrm{(HbVar}$ database). ${ }^{65}$ This mutant involves the substitution of His58 with a Leucine. Our calculations showed an increase in the reorganization energy $(\lambda=0.7001$ $\mathrm{eV})$, and free energy $(\Delta \mathrm{G}=1.993 \mathrm{eV})$ of oxidation similar to the wild type $\mathrm{Hb}$. The corresponding change in the estimated $E^{\circ}$ is $<10 \mathrm{mV}$. MD simulations with the recently reported crystal structure for this variant (3QJD), ${ }^{65}$ gave slightly different ET parameters $\left(\lambda, \Delta G^{\circ}\right)$. The calculations using 3QJD structure give a slightly higher energy gap $(\Delta \mathrm{E})$ for the oxidized state (Table S3), and while it remains similar for the reduced state. The $\lambda$ decreases by $0.0134 \mathrm{eV}, \Delta \mathrm{G}^{\circ}$ increases to $2.02 \mathrm{eV}$, thus giving a lower $E^{\circ}=-0.150 \mathrm{~V}$, suggesting higher equilibrium concentration of oxidized $\mathrm{Hb}$ (i.e. $\mathrm{Hb} \mathrm{M}$ ) compared to the wild type $\mathrm{Hb}$. Thus for the $\mathrm{Hb}$ Kirklareli variant using the crystal 3QJD structure seems necessary to make accurate predictions of relative ET parameters that agree with the experimental information.

Another active site residue (LYS61) forms key H-bonding interactions with the Heme carboxylates and contributes in stabilization of the reduced $\left(\mathrm{Fe}^{2+}\right)$ state. Mutation at this position into a GLU residue forms the $\mathrm{Hb}$ Miyagi variant. This variant (Table 1 and Table S3) shows relatively larger $\Delta \mathrm{E}$ and $\lambda$ values, while a lower $\Delta \mathrm{G}^{\circ}$ and $E^{\circ}=1.87 \mathrm{eV}$ and $-0.296 \mathrm{~V}$ are predicted respectively for the $\mathrm{Hb}$ oxidation. This suggests a higher equilibrium concentration of $\mathrm{Hb} \mathrm{M}$ content in agreement with the experimental fact ( $\mathrm{HbVar}$ database). On the contrary the $\mathrm{Hb} \mathrm{J}$-Buda variant involves a mutation of this LYS61 to a semi-conservative ASN residue and exhibits a lower $\lambda=0.6692 \mathrm{eV}$, and the $\Delta G^{\circ}=1.97 \mathrm{eV}$ is closer to the wild type, while the predicted redox potential $\left(E^{\circ}\right)=-0.204$ $\mathrm{V}$ is lower than wild type and higher than the $\mathrm{Hb}$ Miyagi variant. 


\subsection{Contributions of protein and solvent to the reorganization energies}

As mentioned earlier, the total reorganization energy $(\lambda)$ comprises of the inner-sphere and outer-sphere contributions. Similar to cytochromes, the relatively rigid nature of the Heme cofactor, causes the inner-sphere reorganization energies to be small for $\mathrm{Hb}$ and variants with mutations in the outer-sphere protein environment. ${ }^{70}$ Table 2 shows the protein reorganization energies $\left(\lambda_{\text {prot }}\right)$, calculated by stripping the solvent and ions from MD trajectories and reestimating the AMBER energies with ff19SB force filed. The solvent reorganization energies ( $\left.\lambda_{\text {solv }}\right)$ are then estimated as the difference between the total and protein reorganization energies (i.e. $\left.\lambda_{\text {solv }}=\left(\lambda-\lambda_{\text {prot }}\right)\right)$. Since the relative differences in these energies are more relevant we discuss the unscaled $\lambda$ values. For all the $\mathrm{Hb}$ variants including the wild type, the major contribution to total $\lambda$ comes from the solvent reorganization ( $\lambda_{\text {solv }}: 0.514$ to $\left.0.706 \mathrm{eV}, 73-97 \%\right)$. For the wild type $\mathrm{Hb}$, the solvent contributes $76 \%$, which remains constant for the $\mathrm{Hb} \mathrm{M}$ Boston variant. Nonetheless, the $\lambda_{\text {prot }}$ are non-negligible for the wild type $(0.162 \mathrm{eV}, 24 \%)$ and the Hb M Boston variant $(0.179 \mathrm{eV}, 25 \%)$. The $\mathrm{H} 58 \mathrm{~L}$ (Hb Kirklareli) variant showed a larger protein reorganization $\left(\lambda_{\text {prot }}=0.186 \mathrm{eV}, 27 \%\right.$ ) and solvent reorganization ( $\lambda_{\text {solv }}=0.514 \mathrm{eV}, 73 \%$ ) comparable to the wild type $\mathrm{Hb}$ in response to oxidation.

Table 2. The average vertical ionization energies $(\langle\Delta E\rangle)$ for the protein redox states (solvent molecules were stripped before single point energy estimation with sander), the protein and total reorganization free energies ( $\lambda_{\text {prot }}$ and $\lambda$ ), solvent reorganization energy $\left(\lambda_{\text {solv }}\right)$ for $\mathrm{Hb}$ wild and selected mutants. The relative differences in $\lambda$, and its protein, solvent contributions between the $\mathrm{Hb}$ wild type and variants are important.

\begin{tabular}{|l|c|c|c|c|c|}
\hline Hb $\alpha$ chain Variants & Mutation & $\boldsymbol{\lambda}$ & $\boldsymbol{\lambda}_{\text {prot }}$ & $\boldsymbol{\lambda}_{\text {solv }}=\left(\boldsymbol{\lambda}-\boldsymbol{\lambda}_{\text {prot }}\right)$ & $\begin{array}{c}\% \\
\text { contribution } \\
\text { of } \boldsymbol{\lambda}_{\text {solv }} \text { to } \boldsymbol{\lambda}\end{array}$ \\
\hline Hb & Wild & 0.685 & 0.162 & 0.524 & 76.43 \\
\hline Hb M Boston & H58Y & 0.693 & 0.173 & 0.520 & 75.02 \\
\hline $\begin{array}{l}\boldsymbol{\alpha} \text { analogue of the Hb } \\
\text { Zurich } \boldsymbol{\beta} \text { variant }\end{array}$ & $\mathrm{H} 58 \mathrm{R}$ & 0.722 & 0.179 & 0.543 & 75.21 \\
\hline Hb Miyagi & $\mathrm{K} 61 \mathrm{E}$ & 0.730 & 0.023 & 0.706 & 96.81 \\
\hline Hb J-Buda & $\mathrm{K} 61 \mathrm{~N}$ & 0.669 & 0.032 & 0.638 & 95.28 \\
\hline Hb Kirklareli & $\mathrm{H} 58 \mathrm{~L}$ & 0.700 & 0.186 & 0.514 & 73.38 \\
\hline
\end{tabular}

The H58R variant shows $\lambda_{\text {solv, }}$ and $\lambda_{\text {prot }}$ values similar to the wild type. In the wild type Hb, the sidechain of LYS61 forms an average of two H-bonding interactions with the bulk water and one $\mathrm{H}$-bond with Heme carboxylates (see Figure 4). These $\mathrm{H}$-bond interactions between residue 61 and Heme are lost in the K61E Hb Miyagi variant. The glutamate residue in the K61E Hb variant now forms an average of 5.8 and $4.3 \mathrm{~h}$-bonds with the bulk water molecules in the reduced $\left(\mathrm{Fe}^{2+}\right)$ and oxidized $\left(\mathrm{Fe}^{3+}\right)$ states respectively. The repulsion between the glutamate and Heme carboxylate leads to a significant reorganization of solvent structure $\left(\lambda_{\text {solv }}=0.706 \mathrm{eV}, 97 \%\right)$ forced by increased $\mathrm{H}$-bonding with the surrounding water molecules. The Lys61 residue of the wild type $\mathrm{Hb}$ forms $\mathrm{H}$-bonds with the Heme in $26 \%$ of the frames and thus stabilizes the additional 
negative charge in the reduced $\left(\mathrm{Fe}^{2+}\right)$ state $\left(0.07 \%\right.$ of the frames in oxidized, $\mathrm{Fe}^{3+}$ state). This reduces to negligible $(0.0075 \%$ of the frames) in the $K 61 \mathrm{~N}$ variant and zero in the K61E variant. This explains the unexpectedly lower protein reorganization in these variants in response to oxidation. This suggests that the Lys61 residue place a key role in determining the protein reorganization in response to oxidation and mutation at this site (especially into a negatively charged amino acid) increases $\mathrm{Hb} \mathrm{M}$ formation. The larger protein reorganization $\left(\lambda_{\text {prot }}\right)$ in the wild type prevents faster oxidation to $\mathrm{Hb} \mathrm{M}$, but mutation of Lys to uncharged or negatively charged residues lowers the $\lambda_{\text {prot }}$ facilitating $\mathrm{Hb} \mathrm{M}$ formation. Although there is a corresponding increase in the $\lambda_{\text {solv, }}$ this is likely to be spread out among the a large number of bulk water molecules thus keeping the activation free energy lower than the wild type $\mathrm{Hb}$.
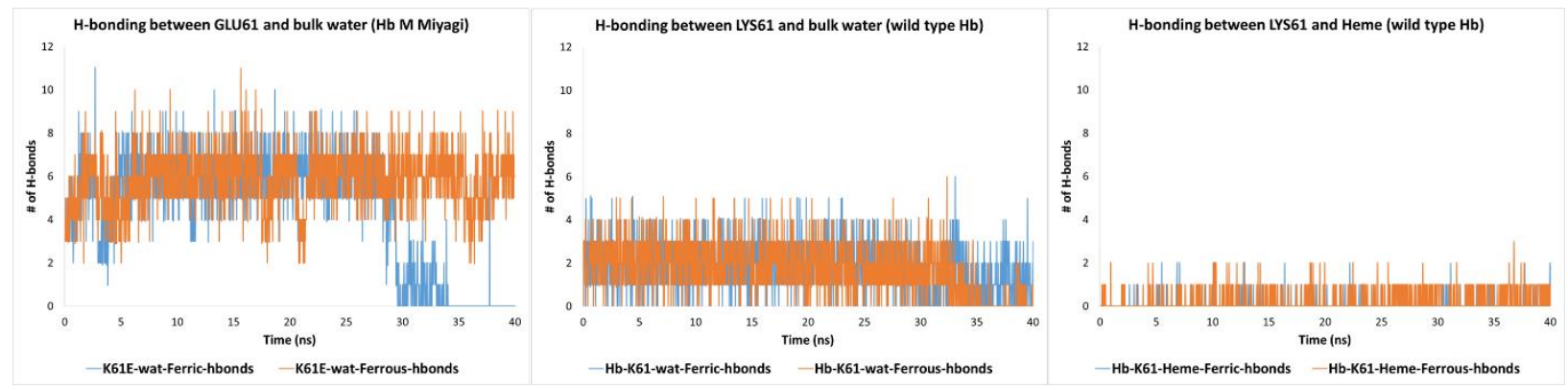

Figure 4. Number of $\mathrm{H}$-bonds formed between the side chain of the residue 61, solvent water and Heme carboxylate in the wild type $\mathrm{Hb}$ (K61) and in the $\mathrm{Hb}$ M Miyagi variant (K61E) during the 40 ns MD simulation.

The $\mathrm{Hb} J$-Buda variant which involves a semi-conservative mutation (K61N) forms an average only $1.1 \mathrm{H}$-bond interactions with the bulk water (not shown), and no interactions with the Heme group. This explains lowest average RMSF calculated for both the K61E and K61N variants (Table $\mathrm{S} 2$ ). Nonetheless, there is a difference of $0.068 \mathrm{eV}$ in $\lambda_{\text {solv }}$ between these two variants with the K61N (Hb J-Buda) being similar to the wild type. This coupled with the larger oxidation free energy difference $(0.13 \mathrm{eV})$ for the $\mathrm{Hb}$ Miyagi (K61E) variant also offers logical explanation for its lower redox potential.

\subsection{Marcus ET parameters for the Cyt b5 (the redox partner of $\mathrm{Hb}$ ).}

As mentioned in the introduction Cyt b5 reduces the oxidized $\mathrm{Hb}(\mathrm{Hb} \mathrm{M}$ ) under physiological conditions i.e. within RBCs. Thus it is important to understand the ET properties of this important redox partner of $\mathrm{Hb}$. Only one Crystal structure for only one human Cyt b5 has been reported (3NER). ${ }^{53}$ Thus this structure was used to model the ET properties of the $\mathrm{Hb}$ redox partner. Protein preparation, Heme parameterization and MD simulations were performed using the protocol mention in section 2 . Table 1 shows the ET parameters $\left(\lambda, \Delta G^{\circ}\right)$ for the oxidation of Cyt b5. The energy gaps for the Cyt b5 are considerably larger than those predicted for $\mathrm{Hb}$ and its variants (see Table S4). This is probably due to the smaller size and associated larger conformational change in the protein structure upon oxidation. Thus the $\lambda$ value for Cyt b5 are also larger than $\mathrm{Hb}$ and giving a scaled $\lambda=0.9299 \mathrm{eV}$. This estimate is larger than the electrochemically determined $\lambda^{28}$ and half of MD based predictions for Cyt b5/Cyt c complex 
reported earlier. ${ }^{71}$ This is expected since the electrochemical adsorption and protein complexation significantly stabilizes the protein dynamics in Cyt b5 in comparison to isolated solution state. The calculated $\Delta \mathrm{G}^{\circ}$ is also higher and was scaled to match the experimental redox potential of $-0.212 \mathrm{~V}$.

\section{Conclusions}

In summary, the answer to the questions asked in the introduction are as follows. 1) The single point mutations studied here, mostly do not disrupt the globin structure. Major exceptions to this are the His $\rightarrow$ Tyr mutations ( $\mathrm{Hb}$ M Boston; distal site and $\mathrm{Hb} \mathrm{M}$ Iwate, proximal). In the later variant a Heme transfer to Tyr is reported in the literature. Mutants K61E, K61N, H58R and H58L show influence on the selected regions of the globin chain (loop 44-54 and region 114-120). 2) All atom MD simulations and average vertical energy gap calculations allow reasonably accurate prediction of Marcus parameters $\left(\lambda, \Delta G^{\circ}\right)$ that are in agreement with literature reports on similar Heme proteins. 3) All the $\mathrm{Hb} \mathrm{M}$ forming mutations (H58Y, K61E and $\mathrm{H} 58 \mathrm{~L}$ ) lead to an increase in the total reorganization energy $(\lambda)$ associated with the $\mathrm{Hb}$ oxidation. Whereas the $\mathrm{Hb} \mathrm{J}$-Buda (K61N) shows a marginal decrease in $\lambda$. The calculated redox potentials are in correspondence with the known propensity of these variants to form Hb M. 4) The solvent reorganization $\left(\lambda_{\text {solv }}\right)$ makes the largest contributions for all the variants (including the wild type). The mutation of the Lys residue has the largest influence on the protein reorganization energies $\left(\lambda_{\text {prot }}\right)$ thus highlighting its role in the stabilization of the reduced $\left(\mathrm{Fe}^{2+}\right)$ state, normal $\mathrm{Hb}$ structure and function. 5) The calculated Marcus ET parameters, redox potentials offer explanation for the corresponding higher and moderate propensity of $\mathrm{Hb}$ oxidation to $\mathrm{Hb} \mathrm{M}$ for the $\mathrm{K} 61 \mathrm{E}$ and $\mathrm{K} 61 \mathrm{~N}$ mutants. Our calculations are also consistent with the reports that $\mathrm{H} 58 \mathrm{~L}$ variant (Hb Kirklareli) undergoes faster autoxidation (lower $E^{\circ}$ than wild type $\mathrm{Hb}$ ).

Finally, this study represents the first attempt to calculate Marcus parameters for the oxidation of $\mathrm{Hb}$ to $\mathrm{Hb} \mathrm{M}$ using all atom MD simulations of the redox states. Our GPU enabled MD simulations, post-processing, calculations and data analysis completes within 4-5 hour/mutant. Thus this methodology can be applied to other $\mathrm{Hb}$ variants and Heme proteins to extract meaningful predictions and has potential to guide experimental studies on most interesting and useful mutations.

\section{Funding information}

This work is partially supported by funding from Additional Competitive Research Grant (ACRG) BITS Pilani (PLN/AD/2019-20/13).

\section{Author contributions}

VAD conceptualized the project, wrote funding proposal, performed literature search, calculations, analyzed results, wrote the manuscript and participated in discussions. JB analyzed the results, provided expert opinion, participated in manuscript writing and discussions. SKV performed preliminary literature and database search, and participated in discussions. 


\section{References}

(1) Forget, B. G.; Franklin Bunn, H. Classification of the Disorders of Hemoglobin. Cold Spring Harb. Perspect. Med. 2013, 3 (2). https://doi.org/10.1101/cshperspect.a011684.

(2) Thom, C. S.; Dickson, C. F.; Gell, D. A.; Weiss, M. J. Hemoglobin Variants: Biochemical Properties and Clinical Correlates. Cold Spring Harb. Perspect. Med. 2013, 3 (3). https://doi.org/10.1101/cshperspect.a011858.

(3) Wajcman, H.; Moradkhani, K. Abnormal Haemoglobins: Detection \& Characterization. Indian Journal of Medical Research. Wolters Kluwer -- Medknow Publications October 2011, pp 538-546.

(4) Kinoshita, A.; Nakayama, Y.; Kitayama, T.; Tomita, M. Simulation Study of Methemoglobin Reduction in Erythrocytes. FEBS J. 2007, 274 (6), 1449-1458. https://doi.org/10.1111/j.1742-4658.2007.05685.x.

(5) Toker, I.; Yesilaras, M.; Tur, F. C.; Toktas, R. Methemoglobinemia Caused by Dapsone Overdose: Which Treatment Is Best? Turkish J. Emerg. Med. 2015, 15 (4), 182-184. https://doi.org/10.1016/j.tjem.2014.09.002.

(6) McRobb, C. M.; Holt, D. W. Methylene Blue-Induced Methemoglobinemia during Cardiopulmonary Bypass? A Case Report and Literature Review. J. Extra. Corpor. Technol. 2008, 40 (3), 206-214.

(7) Bilgin, H.; Özcan, B.; Bilgin, T. Methemoglobinemia Induced by Methylene Blue Pertubation during Laparoscopy. Acta Anaesthesiol. Scand. 1998, 42 (5), 594-595. https://doi.org/10.1111/j.1399-6576.1998.tb05173.x.

(8) Rosen, P. J.; Johnson, C.; McGehee, W. G.; Beutler, E. Failure of Methylene Blue Treatment in Toxic Methemoglobinemia. Association with Glucose-6-Phosphate Dehydrogenase Deficiency. Ann. Intern. Med. 1971, 75 (1), 83-86. https://doi.org/10.7326/0003-4819-75-1-83.

(9) Patnaik, S.; Natarajan, M. M.; James, E. J.; Ebenezer, K. Methylene Blue Unresponsive Methemoglobinemia. Indian J. Crit. Care Med. 2014, 18 (4), 253-255. https://doi.org/10.4103/0972-5229.130582.

(10) Jaffey, J. A.; Harmon, M. R.; Villani, N. A.; Creighton, E. K.; Johnson, G. S.; Giger, U.; Dodam, J. R. Long-Term Treatment with Methylene Blue in a Dog with Hereditary Methemoglobinemia Caused by Cytochrome B5 Reductase Deficiency. J. Vet. Intern. Med. 2017, 31 (6), 1860-1865. https://doi.org/10.1111/jvim.14843.

(11) Lopes, D. V.; Lazar Neto, F.; Marques, L. C.; Lima, R. B. O.; Brandão, A. A. G. S. Methemoglobinemia and Hemolytic Anemia after COVID-19 Infection without Identifiable Eliciting Drug: A Case-Report. IDCases 2021, 23, e01013. https://doi.org/10.1016/j.idcr.2020.e01013.

(12) Scholkmann, F.; Restin, T.; Ferrari, M.; Quaresima, V. The Role of Methemoglobin and 
Carboxyhemoglobin in COVID-19: A Review. J. Clin. Med. 2020, 10 (1), 50.

https://doi.org/10.3390/jcm10010050.

(13) Naymagon, L.; Berwick, S.; Kessler, A.; Lancman, G.; Gidwani, U.; Troy, K. The Emergence of Methemoglobinemia amidst the COVID-19 Pandemic. American Journal of Hematology. Wiley-Liss Inc. August 1, 2020, pp E196-E197. https://doi.org/10.1002/ajh.25868.

(14) Menapace, L. A.; Thein, S. L. COVID-19 and Sickle Cell Disease. Haematologica. Ferrata Storti Foundation November 1, 2020, pp 2501-2504.

https://doi.org/10.3324/haematol.2020.255398.

(15) Ahmed, M. H.; Ghatge, M. S.; Safo, M. K. Hemoglobin: Structure, Function and Allostery. In Subcellular Biochemistry; Springer, 2020; Vol. 94, pp 345-382.

https://doi.org/10.1007/978-3-030-41769-7_14.

(16) Marengo-Rowe, A. J. Structure-Function Relations of Human Hemoglobins. Baylor Univ. Med. Cent. Proc. 2006, 19 (3), 239-245. https://doi.org/10.1080/08998280.2006.11928171.

(17) Lukin, J. A.; Ho, C. The Structure-Function Relationship of Hemoglobin in Solution at Atomic Resolution. Chem. Rev. 2004, 104 (3), 1219-1230.

https://doi.org/10.1021/cr940325w.

(18) Yudin, J.; Verhovsek, M. How We Diagnose and Manage Altered Oxygen Affinity Hemoglobin Variants. Am. J. Hematol. 2019, 94 (5), 597-603.

https://doi.org/10.1002/ajh.25425.

(19) Khanal, R.; Karmacharya, P.; Pathak, R.; Poudel, D. R.; Ghimire, S.; Alweis, R. Do All Patients with Acquired Methemoglobinemia Need Treatment? A Lesson Learnt. J. Community Hosp. Intern. Med. Perspect. 2015, 5 (5), 29079. https://doi.org/10.3402/jchimp.v5.29079.

(20) Ritter, S. Five Decades Of Marcus Theories. Chem. Eng. News 2006, 84 (42).

(21) Qiao, T.; Simmons, J.; Horn, D. A.; Chandler, R.; McLendon, G. Electron Transfer from Cytochrome B5 to Methemoglobin. J. Phys. Chem. 1993, 97 (50), 13089-13091. https://doi.org/10.1021/j100152a010.

(22) Mauk, M. R.; Mauk, A. G. Interaction between Cytochrome B5 and Human Methemoglobin. Biochemistry 1982, 21 (19), 4730-4734. https://doi.org/10.1021/bi00262a032.

(23) Poulos, T. L.; Mauk, A. G. Models for the Complexes Formed between Cytochrome B5 and the Subunits of Methemoglobin. J. Biol. Chem. 1983, 258 (12), 7369-7373. https://doi.org/10.1016/S0021-9258(18)32188-4.

(24) Naito, N. R.; Huang, H.; Sturgess, A. W.; Nocek, J. M.; Hoffman, B. M. Binding and Electron Transfer between Cytochrome B5 and the Hemoglobin $\alpha$ - and $\beta$-Subunits 
through the Use of [Zn, Fe] Hybrids. J. Am. Chem. Soc. 1998, 120 (44), 11256-11262. https://doi.org/10.1021/ja982009v.

(25) Eguchi, L. A.; Saltman, P. Kinetics and Mechanisms of Metal Reduction by Hemoglobin. 2. Reduction of Copper(II) Complexes. Inorg. Chem. 1987, 26 (22), 3669-3672. https://doi.org/10.1021/ic00269a011.

(26) Kidd, R. D.; Baker, E. N.; Brittain, T. A Modeling Study of the Interaction and Electron Transfer between Cytochrome B5 and Some Oxidized Haemoglobins. J. Biol. Inorg. Chem. 2002, 7 (1-2), 23-30. https://doi.org/10.1007/s007750100261.

(27) Ciureanu, M.; Goldstein, S.; Mateescu, M. A. Direct Electron Transfer for Hemoglobin in Surfactant Films Cast on Carbon Electrodes. J. Electrochem. Soc. 1998, 145 (2), 533-541. https://doi.org/10.1149/1.1838299.

(28) Blankman, J. I.; Shahzad, N.; Miller, C. J.; Guiles, R. D. Direct Voltammetric Investigation of the Electrochemical Properties of Human Hemoglobin: Relevance to Physiological Redox Chemistry. Biochemistry 2000, 39 (48), 14806-14812. https://doi.org/10.1021/bi000731b.

(29) Hu, L.; Farrokhnia, M.; Heimdal, J.; Shleev, S.; Rulíšek, L.; Ryde, U. Reorganization Energy for Internal Electron Transfer in Multicopper Oxidases. J. Phys. Chem. B 2011, 115 (45), 13111-13126. https://doi.org/10.1021/jp205897z.

(30) Tipmanee, V.; Oberhofer, H.; Park, M.; Kim, K. S.; Blumberger, J. Prediction of Reorganization Free Energies for Biological Electron Transfer: A Comparative Study of RuModified Cytochromes and a 4-Helix Bundle Protein. J. Am. Chem. Soc. 2010, 132 (47), 17032-17040. https://doi.org/10.1021/ja107876p.

(31) Blumberger, J. Recent Advances in the Theory and Molecular Simulation of Biological Electron Transfer Reactions. Chemical Reviews. American Chemical Society 2015, pp 11191-11238. https://doi.org/10.1021/acs.chemrev.5b00298.

(32) Blumberger, J. Free Energies for Biological Electron Transfer from QM/MM Calculation: Method, Application and Critical Assessment. Phys. Chem. Chem. Phys. 2008, 10 (37), 5651-5667. https://doi.org/10.1039/b807444e.

(33) Krishtalik, L. I. The Medium Reorganization Energy for the Charge Transfer Reactions in Proteins. Biochim. Biophys. Acta - Bioenerg. 2011, 1807 (11), 1444-1456. https://doi.org/10.1016/j.bbabio.2011.07.002.

(34) Kaila, V. R. I.; Johansson, M. P.; Sundholm, D.; Wikström, M. Interheme Electron Tunneling in Cytochrome c Oxidase. Proc. Natl. Acad. Sci. U. S. A. 2010, 107 (50), 2147021475. https://doi.org/10.1073/pnas.1005889107.

(35) Hosseinzadeh, P.; Lu, Y. Design and Fine-Tuning Redox Potentials of Metalloproteins Involved in Electron Transfer in Bioenergetics. Biochim. Biophys. Acta-Bioenerg. 2016, 1857 (5), 557-581. https://doi.org/10.1016/j.bbabio.2015.08.006. 
(36) Page, C. C.; Moser, C. C.; Chen, X.; Dutton, P. L. Natural Engineering Principles of Electron Tunnelling in Biological Oxidation-Reduction. Nature 1999, 402 (6757), 47-52. https://doi.org/10.1038/46972.

(37) Alvarez-Paggi, D.; Castro, M. A.; Tórtora, V.; Castro, L.; Radi, R.; Murgida, D. H. Electrostatically Driven Second-Sphere Ligand Switch between High and Low Reorganization Energy Forms of Native Cytochrome C. J. Am. Chem. Soc. 2013, 135 (11), 4389-4397. https://doi.org/10.1021/ja311786b.

(38) DiCarlo, C. M.; Vitello, L. B.; Erman, J. E. Effect of Active Site and Surface Mutations on the Reduction Potential of Yeast Cytochrome c Peroxidase and Spectroscopic Properties of the Oxidized and Reduced Enzyme. J. Inorg. Biochem. 2007, 101 (4), 603-613. https://doi.org/10.1016/j.jinorgbio.2006.12.006.

(39) Saito, M.; Okazaki, I. A 45-Ns Molecular Dynamics Simulation of Hemoglobin in Water by Vectorizing and Parallelizing COSMOS90 on the Earth Simulator: Dynamics of Tertiary and Quaternary Structures. J. Comput. Chem. 2007, 28 (6), 1129-1136. https://doi.org/10.1002/jcc.20640.

(40) Yusuff, O. K.; Babalola, J. O.; Bussi, G.; Raugei, S. Role of the Subunit Interactions in the Conformational Transitions in Adult Human Hemoglobin: An Explicit Solvent Molecular Dynamics Study. J. Phys. Chem. B 2012, 116 (36), 11004-11009. https://doi.org/10.1021/jp3022908.

(41) Hub, J. S.; Kubitzki, M. B.; de Groot, B. L. Spontaneous Quaternary and Tertiary T-R Transitions of Human Hemoglobin in Molecular Dynamics Simulation. PLoS Comput. Biol. 2010, 6 (5), e1000774. https://doi.org/10.1371/journal.pcbi.1000774.

(42) Fischer, S.; Olsen, K. W.; Nam, K.; Karplus, M. Unsuspected Pathway of the Allosteric Transition in Hemoglobin. Proc. Natl. Acad. Sci. U. S. A. 2011, 108 (14), 5608-5613. https://doi.org/10.1073/pnas.1011995108.

(43) Laberge, M.; Yonetani, T. Molecular Dynamics Simulations of Hemoglobin a in Different States and Bound to DPG: Effector-Linked Perturbation of Tertiary Conformations and HbA Concerted Dynamics. Biophys. J. 2008, 94 (7), 2737-2751. https://doi.org/10.1529/biophysj.107.114942.

(44) Yonetani, T.; Laberge, M. Protein Dynamics Explain the Allosteric Behaviors of Hemoglobin. Biochimica et Biophysica Acta - Proteins and Proteomics. Elsevier September 1, 2008, pp 1146-1158. https://doi.org/10.1016/j.bbapap.2008.04.025.

(45) Mouawad, L.; Perahia, D.; Robert, C. H.; Guilbert, C. New Insights into the Allosteric Mechanism of Human Hemoglobin from Molecular Dynamics Simulations. Biophys. J. 2002, 82 (6), 3224-3245. https://doi.org/10.1016/S0006-3495(02)75665-8.

(46) Samuel, P. P.; Case, D. A. Atomistic Simulations of Heme Dissociation Pathways in Human Methemoglobins Reveal Hidden Intermediates. Biochemistry 2020, 59 (42), 4093-4107. https://doi.org/10.1021/acs.biochem.0c00607. 
(47) Cooper, C. E.; Silkstone, G. G. A.; Simons, M.; Rajagopal, B.; Syrett, N.; Shaik, T.; Gretton, S.; Welbourn, E.; Bülow, L.; Eriksson, N. L.; et al. Engineering Tyrosine Residues into Hemoglobin Enhances Heme Reduction, Decreases Oxidative Stress and Increases Vascular Retention of a Hemoglobin Based Blood Substitute. Free Radic. Biol. Med. 2019, 134, 106-118. https://doi.org/10.1016/j.freeradbiomed.2018.12.030.

(48) Silkstone, G. G. A.; Silkstone, R. S.; Wilson, M. T.; Simons, M.; Bülow, L.; Kallberg, K.; Ratanasopa, K.; Ronda, L.; Mozzarelli, A.; Reeder, B. J.; et al. Engineering Tyrosine Electron Transfer Pathways Decreases Oxidative Toxicity in Hemoglobin: Implications for Blood Substitute Design. Biochem. J. 2016, 473 (19), 3371-3383. https://doi.org/10.1042/BCJ20160243.

(49) Liddington, R.; Derewenda, Z.; Dodson, E.; Hubbard, R.; Dodson, G. High Resolution Crystal Structures and Comparisons of T-State Deoxyhaemoglobin and Two Liganded TState Haemoglobins: T( $\alpha$-Oxy)Haemoglobin and T(Met)Haemoglobin. J. Mol. Biol. 1992, 228 (2), 551-579. https://doi.org/10.1016/0022-2836(92)90842-8.

(50) RCSB PDB - 1HGB: HIGH RESOLUTION CRYSTAL STRUCTURES AND COMPARISONS OF T STATE DEOXYHAEMOGLOBIN AND TWO LIGANDED T-STATE HAEMOGLOBINS: T(ALPHAOXY)HAEMOGLOBIN AND T(MET)HAEMOGLOBIN https://www.rcsb.org/structure/1hgb (accessed Jan 4, 2021).

(51) Anandakrishnan, R.; Aguilar, B.; Onufriev, A. V. H++ 3.0: Automating PK Prediction and the Preparation of Biomolecular Structures for Atomistic Molecular Modeling and Simulations. Nucleic Acids Res. 2012, 40 (W1), W537-W541. https://doi.org/10.1093/nar/gks375.

(52) $\mathrm{H++}$ (web-based computational prediction of protonation states and pK of ionizable groups in macromolecules) http://biophysics.cs.vt.edu/ (accessed Jan 5, 2021).

(53) Parthasarathy, S.; Altuve, A.; Terzyan, S.; Zhang, X.; Kuczera, K.; Rivera, M.; Benson, D. R. Accommodating a Nonconservative Internal Mutation by Water-Mediated Hydrogen Bonding between ß-Sheet Strands: A Comparison of Human and Rat Type B (Mitochondrial) Cytochrome b 5. Biochemistry 2011, 50 (24), 5544-5554. https://doi.org/10.1021/bi2004729.

(54) Li, P.; Merz, K. M. MCPB.Py: A Python Based Metal Center Parameter Builder. J. Chem. Inf. Model. 2016, 56 (4), 599-604. https://doi.org/10.1021/acs.jcim.5b00674.

(55) Case, D. A.; Ben-Shalom, I. Y.; Brozell, S. R.; Cerutti, D. S.; Cheatham, III, T. E.; Cruzeiro, V. W. D.; Darden, T. A.; Duke, R. E.; Ghoreishi, D.; Gilson, M. K.; et al. AMBER18. University of California: San Francisco 2018.

(56) Roe, D. R.; Brooks, B. R. A Protocol for Preparing Explicitly Solvated Systems for Stable Molecular Dynamics Simulations. J. Chem. Phys. 2020, 153 (5), 054123. https://doi.org/10.1063/5.0013849.

(57) Roe, D. R.; Cheatham, T. E. PTRAJ and CPPTRAJ: Software for Processing and Analysis of 
Molecular Dynamics Trajectory Data. J. Chem. Theory Comput. 2013, 9 (7), 3084-3095. https://doi.org/10.1021/ct400341p.

(58) Shapovalov, M. V.; Dunbrack, R. L. A Smoothed Backbone-Dependent Rotamer Library for Proteins Derived from Adaptive Kernel Density Estimates and Regressions. Structure 2011, 19 (6), 844-858. https://doi.org/10.1016/j.str.2011.03.019.

(59) Pettersen, E. F.; Goddard, T. D.; Huang, C. C.; Couch, G. S.; Greenblatt, D. M.; Meng, E. C.; Ferrin, T. E. UCSF Chimera - A Visualization System for Exploratory Research and Analysis. J. Comput. Chem. 2004, 25 (13), 1605-1612. https://doi.org/10.1002/jcc.20084.

(60) Sussner, H.; Mayer, A.; Brunner, H.; Fasold, H. Raman Study on the Two Quaternary States of Unligated Hemoglobin. Eur. J. Biochem. 1974, 41 (3), 465-469. https://doi.org/10.1111/j.1432-1033.1974.tb03288.x.

(61) Van Zundert, G. C. P.; Rodrigues, J. P. G. L. M.; Trellet, M.; Schmitz, C.; Kastritis, P. L.; Karaca, E.; Melquiond, A. S. J.; Van Dijk, M.; De Vries, S. J.; Bonvin, A. M. J. J. The HADDOCK2.2 Web Server: User-Friendly Integrative Modeling of Biomolecular Complexes. J. Mol. Biol. 2016, 428 (4), 720-725. https://doi.org/10.1016/j.jmb.2015.09.014.

(62) Wheeler, K. E.; Nocek, J. M.; Cull, D. A.; Yatsunyk, L. A.; Rosenzweig, A. C.; Hoffman, B. M. Dynamic Docking of Cytochrome B5 with Myoglobin and $\alpha$-Hemoglobin: HemeNeutralization "Squares" and the Binding of Electron-Transfer-Reactive Configurations. J. Am. Chem. Soc. 2007, 129 (13), 3906-3917. https://doi.org/10.1021/ja067598g.

(63) Naito, N. R.; Hui, H. L.; Noble, R. W.; Hoffman, B. M. Determination of the Hemoglobin Surface Domains That React with Cytochrome B5. Biochemistry 2001, 40 (7), 2060-2065. https://doi.org/10.1021/bi0021028.

(64) Jin, Y.; Nagai, M.; Nagai, Y.; Nagatomo, S.; Kitagawa, T. Heme Structures of Five Variants of Hemoglobin M Probed by Resonance Raman Spectroscopy. Biochemistry 2004, 43 (26), 8517-8527. https://doi.org/10.1021/bi036170g.

(65) Bissé, E.; Schaeffer-Reiss, C.; Van Dorsselaer, A.; Alayi, T. D.; Epting, T.; Winkler, K.; Benitez Cardenas, A. S.; Soman, J.; Birukou, I.; Samuel, P. P.; et al. Hemoglobin Kirklareli ( $\alpha \mathrm{H} 58 \mathrm{~L}$ ), a New Variant Associated with Iron Deficiency and Increased CO Binding. J. Biol. Chem. 2017, 292 (6), 2542-2555. https://doi.org/10.1074/jbc.M116.764274.

(66) Tyukhtenko, S.; Rajarshi, G.; Karageorgos, I.; Zvonok, N.; Gallagher, E. S.; Huang, H.; Vemuri, K.; Hudgens, J. W.; Ma, X.; Nasr, M. L.; et al. Effects of Distal Mutations on the Structure, Dynamics and Catalysis of Human Monoacylglycerol Lipase. Sci. Rep. 2018, 8 (1), 1-17. https://doi.org/10.1038/s41598-017-19135-7.

(67) Kang, S. A.; Crane, B. R. Effects of Interface Mutations on Association Modes and Electron-Transfer Rates between Proteins. Proc. Natl. Acad. Sci. U. S. A. 2005, 102 (43), 15465-15470. https://doi.org/10.1073/pnas.0505176102.

(68) Breuer, M.; Zarzycki, P.; Shi, L.; Clarke, T. A.; Edwards, M. J.; Butt, J. N.; Richardson, D. J.; 
Fredrickson, J. K.; Zachara, J. M.; Blumberger, J.; et al. Molecular Structure and Free Energy Landscape for Electron Transport in the Decahaem Cytochrome MtrF. In Biochemical Society Transactions; Portland Press, 2012; Vol. 40, pp 1198-1203. https://doi.org/10.1042/BST20120139.

(69) Simmons, J.; McLendon, G.; Qiao, T. Electron Transfer and Energy Transfer in the Hb:Hb Reductase (Cyt B5) System. J. Am. Chem. Soc. 1993, 115 (11), 4889-4890. https://doi.org/10.1021/ja00064a059.

(70) Sigfridsson, E.; Olsson, M. H. M.; Ryde, U. A Comparison of the Inner-Sphere Reorganization Energies of Cytochromes, Iron-Sulfur Clusters, and Blue Copper Proteins. J. Phys. Chem. B 2001, 105 (23), 5546-5552. https://doi.org/10.1021/jp0037403.

(71) Andrew, S. M.; Thomasson, K. A.; Northrup, S. H. Simulation of Electron-Transfer SelfExchange in Cytochromes c and B5. J. Am. Chem. Soc. 1993, 115 (13), 5516-5521. https://doi.org/10.1021/ja00066a020.

(72) Jiang, X.; Burger, B.; Gajdos, F.; Bortolotti, C.; Futera, Z.; Breuer, M.; Blumberger, J. Kinetics of Trifurcated Electron Flow in the Decaheme Bacterial Proteins MtrC and MtrF. Proc. Natl. Acad. Sci. U. S. A. 2019, 116 (9), 3425-3430. https://doi.org/10.1073/pnas.1818003116.

(73) Marcus, R. A.; Sutin, N. Electron Transfers in Chemistry and Biology. BBA Reviews On Bioenergetics. Elsevier August 1, 1985, pp 265-322. https://doi.org/10.1016/03044173(85)90014-X. 